\title{
Responsabilidade civil do cirurgião-dentista: a importância do assistente técnico
}

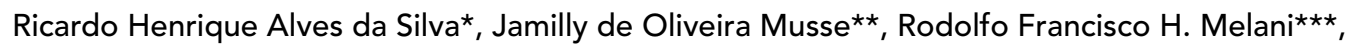
Rogério Nogueira Oliveira***

\section{Resumo}

Introdução: a responsabilidade do cirurgião-dentista pode ser entendida como obrigações de ordem penal, civil, ética e administrativa, às quais está sujeito no exercício de sua atividade. Assim, se comprovado um resultado lesivo ao paciente - por imprudência, imperícia ou negligência -, o cirurgião-dentista estará sujeito às penalidades previstas no Código Civil, sendo obrigado a satisfazer o dano e indenizar segundo a consequência provocada. Em processos cíveis, as partes poderão contratar um assistente técnico para fornecer, aos respectivos advogados, conhecimentos técnicos e científicos inerentes ao tema. Objetivo: informar sobre a importância da atuação de assistentes técnicos em processos cíveis, propiciando às partes uma maior compreensão dos aspectos técnicos, éticos e legais. Conclusão: há a necessidade de um maior conhecimento, por parte dos profissionais em Odontologia, sobre os aspectos éticos e legais que norteiam a profissão.

Palavras-chave: Responsabilidade civil. Odontologia. Perícia.

\section{INTRODUÇÃO}

Ao desempenhar atividade laborativa, além da responsabilidade comum a todas as pessoas como cidadãos, compete ao trabalhador, também, uma responsabilidade específica: a de responder pelos atos cometidos no exercício da profissão.

Particularmente quando são consideradas as profissões da Saúde, essa obrigação de responder pelos atos praticados no desempenho da profissão (responsabilidade profissional) comporta um quádruplo enquadramento: penal, civil, administrativo e ético ${ }^{25}$.

A difusão dos métodos de cura e a consciência do dano sofrido têm conduzido a um aumento significativo do número de pacientes que buscam a reparação por prejuízos em decorrência da culpa profissional. Entretanto, observa-se que os juristas nacionais pouco se dedicaram ao estudo da responsabilidade civil dos cirurgiões-dentistas ${ }^{19}$. Tal enquadramento conduz à reflexão de que, em se tratando de vida humana, não há lugar para culpas pequenas ${ }^{17}$.

E, na atual realidade de mercado - altamente competitivo e no qual busca-se atingir, muitas vezes, apenas o lucro -, observa-se um aumento no número de processos contra profissionais da área da Saúde. Sendo a Odontologia uma das profissões intrinsecamente ligadas à Saúde Pública, a

* Professor doutor - Odontologia Legal - Departamento de Clínica Infantil, Odontologia Preventiva e Social - FORP/USP.

** Doutorado em Odontologia Social pela FO/USP. Docente do Curso de Odontologia da UEFS/Bahia. Odontolegista do Departamento de Polícia Técnica de Feira de Santana, Bahia.

*** Professor doutor do Departamento de Odontologia Social da FOUSP. 
violação das suas exigências não poderia deixar de caracterizar-se como crime ${ }^{27}$.

O chamado mercado da saúde, antes visto como "intocável", hoje recebe diversas denúncias, tanto por parte dos usuários quanto de demais profissionais. O Procon de São Paulo realizou, em 2004, um total de 345.447 atendimentos, dos quais $84 \%$ tiveram orientação ou foram solucionados pelas empresas sem abertura de queixas, $11 \%$ não eram de competência do órgão e os $5 \%$ restantes foram considerados reclamações fundamentadas, ou seja, que se converteram em processo administrativo no Procon ${ }^{9}$.

Em 2005, o Procon-SP recebeu um total de 359.811 reclamações, sendo que as da área da Saúde responderam por $4,70 \%$ desse montante, ou seja, mais de 12.000 reclamações $^{23}$.

Como exemplo, em levantamento realizado no município de Bauru/SP, no primeiro semestre de 2006, foram 6.447 denúncias/reclamações no setor de prestação de serviços, no qual se inclui o setor da Saúde, dentro de um total de 11.956 protocolos do Procon-Bauru ${ }^{5}$.

$\mathrm{O}$ assunto é quase sempre tratado como mero apêndice em trabalhos acerca da responsabilidade civil do médico, esquecendo-se, contudo, de que diversas peculiaridades da atividade, cada vez mais enriquecida com os avanços tecnológicos e científicos, irão influenciar de maneira única e decisiva na resposta jurídica de cada caso concreto ${ }^{14}$.

Por definição, o termo responsabilidade origina-se na palavra latina re-spodere e tem como significado a recomposição, a obrigação do agente causador do dano em repará-1o ${ }^{30}$. Hoje, a responsabilidade jurídica divide-se, de uma forma genérica, em responsabilidade civil e penal, sendo que em ambas há a possibilidade, estabelecida em Lei, da utilização dos serviços de um assistente técnico.

A responsabilidade civil pode ser definida como o dever de reparar o dano causado a outrem, pela prática de um ato ilícito ou inobservância do complexo de normas que norteiam a vida cotidiana ${ }^{11}$. Sua causa geradora é o interesse em restabelecer o equilíbrio jurídico alterado ou desfeito pela lesão, por meio da indenização pecuniária ${ }^{25}$.

Os atos humanos devem sempre ser ou estar de acordo com os preceitos legais. Dessa maneira, os atos que contrariem um dispositivo legal são ilegais, por apresentarem-se contrários ao Direito. E, segundo a Lei Civil Brasileira, é ato lícito aquele que se fundamenta no Direito e ato ilícito o que contraria a lei, ou seja, afronta o Direito, fugindo das determinações legais, sendo, consequentemente, um crime, que pode ser civil ou criminal, de acordo com a lei que venha a ser ofendida pelo comportamento em questão ${ }^{7}$.

Fazem parte dos trâmites do processo civil: o autor (aquele que formula pedido em juízo), o réu (aquele contra quem tal pedido se dirige), os advogados, o juiz e os assistentes técnicos ${ }^{20}$.

O assistente técnico, foco central deste artigo, é tido como auxiliar da parte, tendo por obrigação concordar, criticar ou solicitar complementações ao laudo do perito oficial, por meio de seu parecer, cabendo ao juiz, pelo princípio do livre convencimento, analisar seus argumentos ${ }^{18}$. Vale ressaltar, também, que a atuação do assistente técnico é parcial, ou seja, ele defende uma das partes da lide judicial, diferentemente do perito, que deve ser imparcial.

Assim, esta revisão de literatura tem como objetivo informar acadêmicos, profissionais de Odontologia e advogados sobre a responsabilidade civil do cirurgião-dentista e ressaltar a importância da presença de assistentes técnicos em processos cíveis na área odontológica.

\section{REVISÃO DE LITERATURA}

A responsabilidade civil é um tema cada vez mais presente no Direito brasileiro. Isso ocorre em função de relevantes avanços quanto à legislação, com grande modificação no reconhecimento do povo como cidadão, principalmente com a Constituição da República Federativa do Brasil, de 1988, que instituiu, além de outras garantias, o direito à saúde. Assim, confirmou os cidadãos como entes 
participativos no meio social, fazendo com que todos buscassem com mais fervor os seus direitos. Consequentemente, houve um grande aumento do número de ações indenizatórias a fim de reparar os danos causados por profissionais da Saúde ${ }^{30}$.

Além disso, com o advento da Lei $n^{\circ}$. 8078, de 11 de setembro de 1990, denominada Código de Defesa do Consumidor, o cirurgião-dentista passou a ser considerado fornecedor de serviços. Isso acirrou os debates sobre a questão, bem como elevou o número de casos levados ao Poder Judiciário, no sentido de ressarcimento de danos por erro profissional ${ }^{8}$.

O Código de Defesa do Consumidor define serviço como "qualquer atividade fornecida no mercado de consumo mediante remuneração", estando a atuação do cirurgião-dentista sujeita a tal regulamentação também ${ }^{29}$.

Tais danos são obrigações derivadas de atos ilícitos por meio de ações, culposas ou dolosas, praticadas como infração a uma conduta a ser seguida $^{12}$. Nesse sentido, de acordo com o artigo 927 do Código Civil Brasileiro (2002) "aquele que por ato ilícito causar dano a outrem fica obrigado a repará-lo"3.

Portanto, todo lesado tem o direito de buscar a reparação do dano que lhe foi causado, o que torna ainda mais delicada a relação profissionalpaciente: hoje, a maioria dos procedimentos realizados pelos cirurgiões-dentistas ficam sujeitos à análise de qualidade, podendo esses profissionais responder civilmente pelos seus atos ${ }^{22}$.

\section{Da responsabilidade objetiva e subjetiva}

Tendo em vista os fundamentos da responsabilidade civil, essa se classifica em responsabilidade objetiva e responsabilidade subjetiva ${ }^{30}$.

A responsabilidade subjetiva funda-se no conceito de que, para haver a responsabilização do agente causador do dano, imprescindível se faz a comprovação da culpa, ou seja, o agente deve agir com vontade própria e consciência ${ }^{16}$.

$\mathrm{Na}$ culpa, há sempre a violação de um dever preexistente. Se esse dever se funda em um contrato, a culpa é contratual; se no princípio geral do Direito, que manda respeitar a pessoa e os bens alheios, a culpa é extracontratual ou aquiliana ${ }^{21}$.

A lei impõe, entretanto, a certas pessoas e em determinadas situações, a reparação de um dano cometido sem culpa. Quando isso acontece, diz-se que a responsabilidade é legal ou objetiva, porque prescinde da culpa e se satisfaz apenas com o dano e o nexo de causalidade ${ }^{19}$.

Se pensarmos no enquadramento da responsabilidade em Odontologia, essa apresentar-se-á como subjetiva, conforme o Código de Defesa do Consumidor (1990) que legisla, em seu artigo 14: "O fornecedor de serviços responde, independentemente da existência de culpa, para reparação dos danos causados aos consumidores por defeitos relativos à prestação dos serviços, bem como por informações insuficientes ou inadequadas sobre sua fruição ou riscos. $\S 4^{\circ}$. A responsabilidade dos profissionais liberais será apurada mediante a verificação da culpa".

\section{Processo de responsabilidade civil}

Processo consiste no instrumento ou meio utilizado para solucionar conflitos de interesse regulados pelo direito existente entre pessoas diferentes, denominadas partes (autor e réu) ${ }^{11}$. Normalmente, o processo de responsabilidade civil demanda tempo considerável, podendo variar de alguns meses a anos, tendo em vista a necessidade, na maioria dos casos, de realização de perícia especializada ${ }^{15}$.

O Código de Processo Civil (Lei n ${ }^{\circ} 5869$, de 11 de janeiro de 1973) descreve no Título 7, capítulo III, artigos 276 a 278, todas as etapas pertinentes a um processo da área cível ${ }^{4}$, conforme resumimos nos esquemas ilustrados nas figuras 1 e 2 .

$\mathrm{Na}$ petição inicial, o autor, representado pelo seu advogado, fará a exposição dos problemas e formulará os quesitos ${ }^{4}$. Em geral, o autor precisa provar o nexo causal entre o ato praticado pela parte adversa e o dano experimentado ${ }^{16}$. De posse 


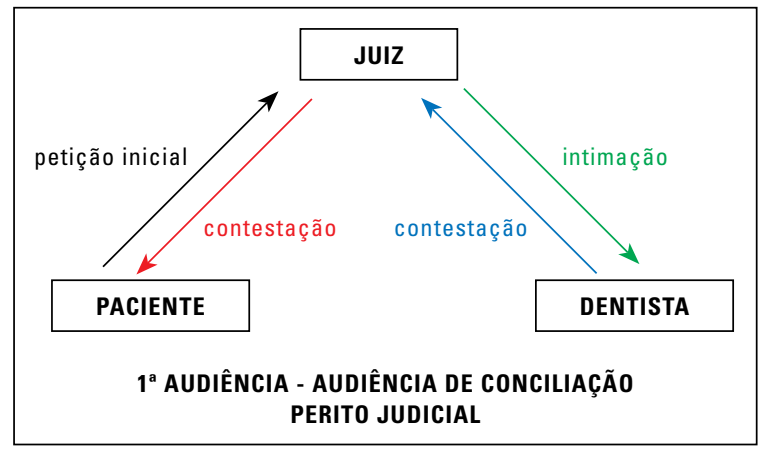

FIGURA 1 - Trâmite processual civil (fase inicial).

desse documento, o juiz citará e intimará o réu, designando a audiência de conciliação, a ser realizada no prazo de trinta dias. Não obtida a conciliação, resposta escrita ou oral acompanhada de documentos ou quesitos será apresentada pelo advogado do réu, defendendo-o da acusação que lhe está sendo imputada ${ }^{4}$.

Havendo necessidade de perícia, o juiz indicará um perito de sua confiança para realizá-la, o que resultará na elaboração de um laudo ${ }^{4}$. É importante lembrar que o juiz poderá solicitar a perícia mesmo sem o pedido das partes litigantes. Além do perito nomeado pelo juiz, as partes litigantes, se assim o desejarem, poderão nomear seus assistentes técnicos, que acompanharão a realização da perícia e apresentarão seus respectivos laudos técnicos, acrescentando-os ao processo ${ }^{6}$.

Após a realização da instrução processual, ou seja, depois de examinadas todas as provas, o juiz proferirá sentença, conforme seu convencimento, não precisando seguir as mesmas conclusões da perícia técnica ${ }^{4}$. Dessa sentença, a parte prejudicada poderá apresentar recurso de apelação ao tribunal competente.

\section{Assistência técnica}

No sistema do Código de Processo Civil (1973), as partes são livres para indicar seus assistentes técnicos, sempre em número de um e cuja aceitação é espontânea ${ }^{15}$.

Assim, assistente técnico é o rótulo que a Lei

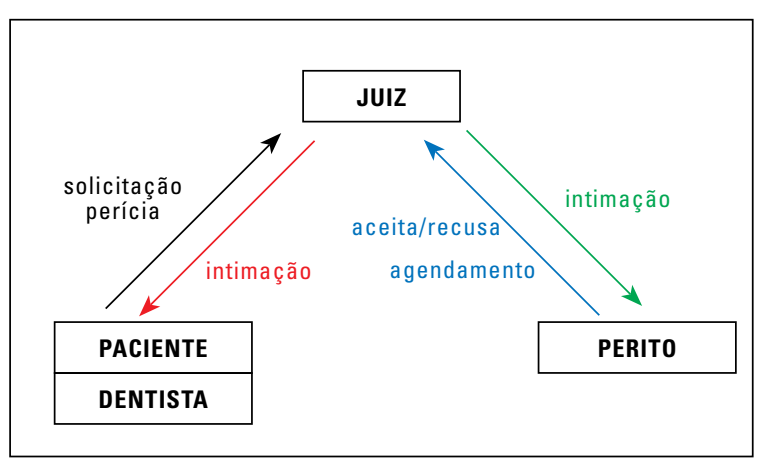

FIGURA 2 - Trâmite processual civil - perícia odontológica.

processual civil empresta ao profissional especializado em determinada área, indicado e contratado por uma das partes, no sentido de prestar ajuda na elaboração da prova pericial. Em tese, eles possuem os mesmos privilégios dos peritos - como ouvir testemunhas, solicitar documentos e obter as devidas informações -, tendo diferenciações somente relativas às questões de prazo, pois o do assistente técnico é de apenas 10 dias após a entrega do laudo pelo perito ${ }^{13}$.

Preferencialmente, o especialista deve ser um profissional que milite na área de Odontologia Legal, haja vista todo o trâmite processual envolvido, bem como a necessidade de conhecimento dos aspectos jurídicos envolvidos em uma perícia, além do auxílio ao advogado na composição de documentos e na estruturação da defesa da parte.

O Código de Processo Civil (1973), no Título I, capítulo V, Seção II, artigo 50, que trata da assistência técnica, confirma a possibilidade de atuação de terceiros no processo, como auxiliares de uma das partes, desde que esses tenham interesse jurídico em que a sentença seja favorável a uma das mesmas ${ }^{4}$.

\section{DISCUSSÃO}

O conhecimento dos direitos e deveres, bem como o respeito ao Código de Ética, é condição fundamental para o correto exercício de qualquer profissão, inclusive as relacionadas à Saúde e à coletividade, como a Medicina e a Odontologia ${ }^{1}$. 
Ao desempenhar suas atividades de rotina, além da responsabilidade comum a todas as pessoas como cidadãos, compete ao trabalhador uma responsabilidade específica, a de responder por atos cometidos no exercício da profissão ${ }^{24}$.

No ato em que o cirurgião-dentista aceita alguém como paciente, estabelece-se entre as duas partes um contrato de prestação de serviços, que deve ser entendido como obrigação de resultado ou obrigação de meio. A de resultado é aquela em que o credor tem o direito de exigir do devedor a produção de um resultado, enquanto, na de meio, o devedor se obriga tão somente a usar de prudência e diligência normais na prestação de certos serviços para atingir um resultado, sem, contudo, se vincular a obtê-lo ${ }^{25}$.

Observa-se que a Odontologia apresenta uma tendência atual de ser enquadrada como obrigação de resultado, em virtude de muitos profissionais prometerem resultados "milagrosos", assim como da falta de divulgação de insucessos na prática odontológica e do uso de artifícios inadequados de propaganda (antes e depois), levando o paciente a entender que todo procedimento em Odontologia terá sucesso e independe de outros fatores (tais como resposta biológica e cooperação do paciente).

Distante é a época em que a relação profissional-paciente era completamente baseada na confiança, sem tantos questionamentos e exigências por parte do paciente ${ }^{22}$. Nos dias de hoje, não resta a menor dúvida sobre a consciência e capacidade cognitiva dos pacientes quanto à relação de contrato que se estabelece com o profissional ${ }^{2}$, além de uma maior exigência quanto às informações sobre os serviços prestados.

Muitas vezes, incentivados pelo seu círculo social ou pela própria mídia, uma parte significativa desses pacientes/clientes busca algum ressarcimento monetário nos casos de erros advindos por culpa do cirurgião-dentista, procurando na máquina judiciária todo amparo para essa prestação. Porém, a atividade judiciária, muitas vezes, foge ao controle técnico e científico que rege a Odontologia, assim como em qualquer outra área da Saúde ${ }^{30}$.

Dessa forma, o cirurgião-dentista deve realizar todo trabalho baseado numa técnica coerente e de forma diligente, sem esquecer que, em um processo, a peça fundamental é o prontuário odontológico ${ }^{28}$.

Havendo o dano e estando o cirurgião-dentista sujeito a um processo na área cível, é hora de localizar a documentação do paciente que move a ação e contratar um bom advogado e um assistente técnico experiente na área da Odontologia Legal.

O cirurgião-dentista e o paciente podem estar representados, legalmente, por qualquer cirurgiãodentista, uma vez que a Lei $n^{\circ} .5081$ (1966), que regulamenta o exercício da Odontologia, estabelece em seu artigo $6^{\circ}$ sua competência para proceder à perícia odontolegal em foro civil, criminal, trabalhista e em sede administrativa.

Quanto à documentação odontológica, as provas a serem apresentadas pelo profissional são pré-constituídas, ou seja, são produzidas oportunamente, ou não servirão para esse $\mathrm{fim}^{24}$. $\mathrm{O}$ profissional deve elaborar, ao longo do tempo, o prontuário do paciente. Do contrário, a ficha que apresenta em juízo, forjada no ato de defesa ou trazendo apenas anotações relativas aos custos e pagamentos, entremeadas de poucas e esparsas informações acerca do tratamento, será irrelevante ${ }^{9}$.

Assim, o prontuário odontológico deverá conter todas as ocorrências, suas consequências verificadas ao longo do atendimento, bem como todas as providências tomadas, já que a falta ou falhas nessa documentação comprometerão a sua validade sob o aspecto legal.

Um prontuário composto de registro da anamnese, ficha clínica, plano de tratamento, receitas, atestados, modelos, radiografias e orientações pósoperatórias e/ou sobre higienização é passível de ser realizado por todo e qualquer profissional ${ }^{26}$.

Desta forma, todas as orientações referentes à documentação odontológica, bem como um relato 
fiel aos fatos ocorridos, serão abordadas pelo assistente técnico, podendo consultar especialistas na área do processo, a fim de procurar um melhor posicionamento na defesa de seu cliente. No entanto, a necessidade do conhecimento da Legislação brasileira, bem como da Deontologia e Diceologia específicas, somado à experiência prática da atividade aponta, como postura prudente, para a indicação de um profissional da Odontologia Legal.

Ainda em relação à assistência técnica, há uma série de sugestões, direcionadas especificamente aos advogados, no sentido de pautar sua atuação, em relação ao assistente técnico, dentro da nova sistemática que rege o processo civil no que tange à prova pericial ${ }^{18}$ :

- Procurar contatar o assistente técnico antes mesmo do início da ação, pois esse poderá tornarse um consultor técnico em todas as fases do processo, haja vista o desconhecimento do profissional da área jurídica quanto aos aspectos técnicos da Odontologia.

- Antecipar-se à nomeação do perito oficial, permitindo ao assistente técnico tomar conhecimento do processo, realizar um levantamento dos dados e propor sugestões de quesitos.

- Avisar ao assistente técnico da nomeação do perito oficial, fornecendo seu nome, endereço e telefone, para que ele possa contatá-lo com facilidade, a fim de fornecer-lhe as informações necessárias e fazer as solicitações que eventualmente ocorram.

- Inteirar-se com o assistente técnico dos honorários que usualmente são cobrados pelos peritos oficiais naquele tipo de ação, que poderão ser guiados pelas tabelas profissionais ou costumes locais.

- Não manifestar-se com relação aos atos praticados pelo perito oficial sem discutir o assunto com o assistente técnico, pois muitas vezes envolvem temas de caráter restrito à categoria profissional em que se inserem esses profissionais.

- Dar ciência ao assistente técnico do depósito dos honorários do perito oficial, a partir do qual a perícia pode ter início a qualquer momento.

- Comunicar ao assistente técnico sobre a determinação para início da perícia, fornecendo-lhe o completo teor do despacho, pois muitos juízes costumam fixar dia e hora para a realização da vistoria que, preferencialmente, deve contar com a presença do assistente técnico.

- Informar o assistente técnico de qualquer publicação sobre despacho relacionado à prova pericial, direta ou indiretamente.

- Fornecer ao assistente técnico, imediatamente, informação sobre publicação relativa à entrega do laudo pericial por parte do perito oficial.

- Tomar conhecimento, e passar ao assistente técnico, o teor da manifestação do assistente técnico da parte contrária sobre o laudo pericial entregue pelo perito oficial.

- Discutir com o assistente técnico o conteúdo de seu parecer sobre o laudo pericial emitido, pois o seu trabalho deve obedecer a uma linha de raciocínio e estratégia elaborada pelo advogado na construção da lide.

\section{CONSIDERAÇÕES FINAIS}

É possível concluir que o assistente técnico pericial desempenha uma função significativa em processos de responsabilidade profissional, pelo fornecimento de informações técnicas, biológicas e legais, devendo-se optar, preferencialmente, por profissionais da área de Odontologia Legal, haja vista que a atuação desse profissional não limita-se ao conhecimento técnico da área processada, mas a todo o trâmite do mesmo.

Observa-se, ainda, que as orientações de um assistente técnico podem trazer para o cirurgiãodentista vantagens, tais como: melhor organização da documentação odontológica, maior conhecimento de seus direitos e deveres e, sobretudo, maior segurança na sua atuação profissional. 


\title{
Surgeon dentist's civil liability: The technical assistant's importance
}

\begin{abstract}
Introduction: The dentist's liability can be understood as the criminal, civil, ethical and administrative obligation that they have in their professional exercise. Thus, when producing a harmful result to the patient, due to imprudence, ineptitude or recklessness, the dentists will be liable to the foreseen penalties on the Civil Code, where the compensation will be obligatory to satisfy the damage according to the reached consequence. In these types of processes, the involved parts will be able to contract a technical assistant to supply the respective lawyers about biological, technician and professional knowledge. Aim: This paper aim to report about the technical assistant's importance, in the performance of each one of the involved parts in a civil process. Conclusion: It is necessary a major knowledge, by dentists, about legal and ethical aspects in the professional activity.
\end{abstract}

Keywords: Civil liability. Dentistry. Peritial.

\section{REFERÊNCIAS}

1. BARBERINO, D. Sigilo profissional. In: GALVÃO, L. C. C.; BARBOSA, M. B. B. Seminários avançados em Odontologia legal. Feira de Santana: Ed. da UEFS, 2002.

2. BLOISE, W. A responsabilidade civil e o dano médico. 2. ed. Rio de Janeiro: Forense, 1997

3. BRASIL. Código Civil Brasileiro. 3. ed. São Paulo: Manole, 2004.

4. BRASIL. Lei $n^{\circ}$. 5.869, de 11 de janeiro de 1973. Institui o Código de Processo Civil. Diário Oficial da União, Brasília, DF, 11 jan. 1973.

5. CAMARGO, A. Prestador de serviço desrespeita CDC. Jornal da Cidade, Bauru, 13 ago. p. 10, 2006.

6. COUTO, M. U. Assistência simples no direito processual civil. São Paulo: R. dos Tribunais, 1983.

7. DARUGE, E.; MASSINI, N. Exercício lícito da Odontologia no Brasil. In: DARUGE, E. Direitos profissionais na Odontologia. São Paulo: Saraiva, 1978. p. 401-409.

8. DIAS-RIBEIRO, A. R. M. Erros profissionais e seus aspectos jurídicos em Odontologia legal. Rev. Bras. Odontol., Rio de Janeiro, v. 53, n. 3, p. 41-43, 1996.

9. DINHEIRO. Teles e bancos são as empresas que mais recebem reclamações. Folha on Line, São Paulo, 15 mar. 2005 Disponível em: <http://www1.folha.uol.com.br/folha/dinheiro/ ult91u94354.shtml>. Acesso em: 16 set. 2006.

10. DINIZ, M. H. Curso de Direito Civil Brasileiro. 13. ed. São Paulo: Saraiva, 1999.

11. FARAH, E. E.; FERRARO, L. Como prevenir problemas com os pacientes: responsabilidade civil. 3. ed. São Paulo: Quest, 2000.

12. FELIX, A. F. C.; SOUZA, A. P. Responsabilidade civil médica e hospitalar. Belo Horizonte: Del Rey, 2001.

13. FRANÇA, G. V. Medicina legal. 7. ed. Rio de Janeiro: Guanabara Koogan, 2004

14. FREITAS-FILHO, A. et al. Responsabilidade civil do cirurgiãodentista. In: GALVÃO, L. C. C.; BARBOSA, M. B. B. Seminários avançados de Odontologia Legal. Feira de Santana: Ed. da UEFS, 2002. p. 21-26.

15. GONÇALVES, C. R. Responsabilidade civil. 7. ed. São Paulo: Saraiva, 2002

16. KFOURI-NETO, M. Culpa médica e ônus da prova. São Paulo: R. dos Tribunais, 2002.

17. KFOURI-NETO, M. Responsabilidade civil do médico. 4. ed. São Paulo: R. dos Tribunais, 2001.

18. MAIA, F. O assistente técnico no Código de Processo Civil 2006. Disponível em: <http://www.precisao.eng.br/artigos/ assistec.html>. Acesso em: 20 abr. 2006.

19. OLIVEIRA, M. L. L. Responsabilidade civil odontológica. Belo Horizonte: Del Rey, 1999.
20. OLIVEIRA-FILHO, C. V. Diferenças fundamentais entre o assistente simples e o assistente litisconsorcial no Direito Processual Civil brasileiro. Disponível em: <http://jus2.uol. com.br>. Acesso em: 20 abr. 2006.

21. PEDROTTI, A. I. Responsabilidade civil. 2. ed. São Paulo: Liv. Ed. Univ. de Direito, 1995.

22. $P E R E Z$, J. A. A. A responsabilidade civil do cirurgião-dentista em face do Código de Defesa do Consumidor. Disponível em: <http://www.direitobancario.com.br/doutrinaacessolivre> Acesso em: 5 ago. 2006.

23. PROCON. Relatório Técnico 2005. Disponível em: <http:// www.procon.sp.gov.br/reclamacoes.asp>. Acesso em: 23 set. 2006.

24. SAMICO, A. H. R.; MENEZES, J. D. V.; SILVA, M. Aspectos éticos e legais do exercício da Odontologia. 2. ed. Rio de Janeiro: CFO, 1994.

25. SILVA, M. Compêndio de Odontologia legal. Rio de Janeiro: Medsi, 1997.

26. SILVA, M. Documentação em Odontologia e sua importância jurídica. Rev. Odontol. Soc., São Paulo, v. 1, n. 1/2, p. 1-3, 1999.

27. SILVA, R. H. A. Atividade ilícita profissional em Odontologia: análise do conhecimento de acadêmicos, magistrados e entidades promotoras de cursos de aperfeiçoamento e/ou especialização, no município de Bauru-SP. 2005. Dissertação (Mestrado)-Faculdade de Odontologia de Bauru, Universidade de São Paulo, Bauru, 2005.

28. SIMONETTI, F. A. A. Responsabilidade civil do cirurgiãodentista. Rev. Assoc. Paul. Cirur. Dent., São Paulo, v. 53, n. 6 , p. 449-451, nov./dez. 1999.

29. SOUZA, N. V. de. Breves considerações sobre a responsabilidade civil de dentistas. Proteção ao paciente. In: GORAB, R.; FELLER, C. Atualização na clínica odontológica: cursos antagônicos. São Paulo: Artes Médicas, 2000. p. 593-620.

30. WILLEMANN, C. A responsabilidade civil do cirurgião dentista não-autônomo nas situações de emergência das atividades hospitalares. Disponível em: <http://jus2.uol.com. br/doutrina/texto.asp>. Acesso em: 20 set. 2006.

Endereço para correspondência

Ricardo Henrique Alves da Silva

Faculdade de Odontologia de Ribeirão Preto - USP

Departamento de Clínica Infantil, Odontologia Preventiva e Social

Avenida do Café, s/n, Bairro Monte Alegre

CEP: 14.040-904 - Ribeirão Preto / SP

E-mail: ricardohenrique@usp.br 